\title{
Mountain research in protected areas in the Carpathians - a brief overview
}

\author{
Juraj Švajda
}

Keywords: Forum Carpaticum, research, sustainable development

\section{Abstract}

The Carpathians, as European mountains with exceptional natural and cultural values, are facing many challenges connected with sustainable development. Research provides important information for decision makers, planners and managers on how to deal with these issues. Here, we analyse by a systematic quantitative literature review 520 contributions to Forum Carpaticum conferences. Most of the research was conducted in Romania and Poland by universities and research institutes. Particular attention was paid to the topics of conservation and biodiversity, forestry and ecology, and land use and land cover change. Field research and data analysis, including modelling using modern tools, are among the most frequent approaches or technologies used for research. Research patterns potentially reflect the demand for, and supply of information and analysis in particular geographical areas and on specific topics. There are also growing impacts of technology and social media in this field. Our results could be used for indications of key future research directions and to identify current gaps in research in the Carpathians.

The Carpathians are a prominent European mountain range with a unique natural and cultural diversity. They are experiencing rapid socio-economic transformation, which creates a number of challenges for sustainable development (land use change, depopulation of marginal areas, environmental degradation, pressure on natural resources). Research is a particularly important tool for decision makers, planners and managers for how to deal with these challenges. In this article, we offer a brief overview of the proceedings from the first four Forum Carpaticum conferences (2010, 2012, 2014, 2016), assessing who does the research and where, and what the main research themes are. The results could be used to identify current gaps and key future research directions.

We used a systematic quantitative literature review methodology to identify topics in the contributions to Forum Carpaticum. For each oral abstract or poster presentation, information was coded into a database for the following fields: where the research was conducted (country, and location of any protected area mentioned in the paper); who did the research (number of authors, lead author's origin and affiliation / institution type); what the main theme of the research was. Finally, we also recorded what approaches, methods or technologies were used for the research.

Across the four sets of proceedings, there were 520 contributions by nearly 1800 authors (some of whom had multiple inputs). The lead authors associated with most of the research presented at the conferences were affiliated with institutions located in Carpathian countries (Poland 24.4\%, Romania 23.7\% and Slovakia $14.8 \%$ ). Countries outside the Carpathians were mostly represented by authors from the United States $(3.7 \%)$. Most of the research was conducted in Romania (23.7\%) and Poland (21.2\%). Our results show that research is still largely the domain of universities (58.1\%) and research institutes (35.0\%). There is scope for governmental institutions, such as national park authorities, as well as NGOs and private companies with research in their portfolios, to carry out considerably more research, especially in collaboration with universities and research institutes. The majority of contributions were prepared as team work (only 20\% of contributions were by a single author). We also analysed whether the research was conducted in protected areas, basing this on information in the contributions themselves. Only $15.8 \%$ of contributions named specific protected areas (including not just national park but also Natura 2000 sites, biosphere reserves, world heritage sites and forest reserves) as their study areas. However, we know that the proportion of researchers working in protected areas is in reality higher. It was certainly a missed opportunity that researchers didn't highlight the fact in their papers, not least because research is a priority in some categories of protected area (or internationally recognized areas): these labels could serve to attract both funding and researchers.

We aimed to cluster all contributions according topics which were outlined in the texts (conservation and biodiversity $18.3 \%$, forest and ecology $16.7 \%$, land use and land cover $12.1 \%$ ). Although there is often overlap between themes, it is possible to discern a shift towards an agenda which reflects current issues (e.g. tourism, ecosystem services, water resources, or climate change, as well as impacts of human activity on biodiversity). Just one demonstration of this shift: while a few years ago a significant amount of work focused on air quality assessment (concentration of pollutants), a larger proportion of later work analyses the impact of air pollution on living ecosystems, and recent research models future scenarios or adaptation strategies to environmental change. There is still great potential for comparative case studies and long-term monitoring, in both social and economic sciences.

Approximately $25 \%$ of contributions were supported by grants, as stated in the final section of the texts analysed, and there is certainly scope for a more 
in-depth analysis of the sufficiency of funds and possible resources (domestic, EU or international funds and projects).

Lastly, we focused on the approaches, methods and technologies used for research. We tried to identify the prevailing content of contributions (some focused on collecting data, some on analysing and others on interpreting it). However, often a combination of approaches was used. For example, direct field surveys are frequently supplemented by analysis of existing data from databases, and current changes in the field are analysed by use of satellite data. We also see an increasing use of modern tools, depending on the topic of research (e. g. habitat modelling using GIS tools, or the genetic analysis of species). Analysis of historical maps and photographs has been replaced by remote sensing for studies of land use and changes in land cover. Purely theoretical contributions accounted for only $22.1 \%$ of the corpus analysed. Field research $(37.7 \%)$ is the most common way of collecting data in the natural sciences; questionnaires and interviews for data collection are used mostly in social sciences. Contributions focused mainly on data processing; GIS modelling including the analysis of satellite imagery was a feature of $37.4 \%$ of the papers.

Research patterns potentially reflect the demand for, and supply of, information and analysis in particular geographical areas and on specific topics. The current shift towards research that focuses on or uses new technologies and social media is visible also in the subtitles of the individual conference proceedings. Integrating nature and society towards sustainability in 2010 linked research with practice in the field of coupled human-environmental systems in mountain regions. The 2012 topic, From data to knowledge - from knowledge to action, stressed the need for information, knowledge and follow-up steps in management. Local responses to global challenges in 2014 addressed global challenges in the local and regional contexts. The topic for 2016, Future of Carpathians - smart, sustainable, inclusive, reflected debates around the main priorities for the near future (technologies, innovations, adaptation strategies, green jobs etc.).

The Science for Carpathians (S4C) initiative, a platform connecting scientists and fostering dialogue between research, policy and practice, aims to establish a new research agenda for the Carpathians, for 2016-2020, and is still open for comments. The aim of the agenda is to highlight all the issues which are of particular importance in terms of sustainable mountain development in the region. Other ideas include reinforcement of cooperation with the Alps, which are facing similar issues, e.g. a regular symposium for research in protected areas, or creating of new research portal for Carpathian protected areas which could serve not only for data storage, reporting and tracking, but also for highlighting research needs. Finally, it should be noted that research is very important for evidence-based decision making. Maybe we as researchers should focus more on how to increase support for research into protected areas, and how, using objective facts, we might influence and shape public opinion (through citizen science), as well as the attitudes of policy makers. This, in the so-called post-truth era, is the real challenge.

\section{References}

Boltižiar, M. (eds.) 2012. Conference Abstracts of the $2^{\text {nd }}$ Forum Carpaticum. From Data to Knowledge, from Knowledge to Action.

Kruhlov, I. \& B. Prots (eds.) 2014. Forum Carpaticum 2014: Local Responses to Global Challenges. Conference Abstracts. September 16-18, 2014, Lviv.

Ostapowicz, K. \& J. Kozak (eds.) 2010. Conference Proceedings of the $1^{\text {st }}$ Forum Carpaticum. Integrating Nature and Society Towards Sustainability.

Verga M. \& G. Manea (eds.) 2016. Forum Carpaticum 2016: Future of the Carpathians: Smart, Sustainable, Inclusive. Conference Abstracts. September 28-30, 2016, Bucharest.

\section{Author}

\section{Juraj Švajda}

is an assistant at the Faculty of Natural Sciences, University of Matej Bel, Banská Bystrica (Slovakia). His professional career is devoted to protected area management, the impact of tourism, and the human dimension of natural resources management and ecosystem services. For many years, he was an active member of the IUCN World Commission on Protected Areas and the Slovak Committee of the UNESCO Man and Biosphere Programme. E-mail: juraj. svajda@gmail.com 